\title{
Pattern-Sensitive Epilepsy. I: A Demonstration of a Spatial Frequency Selective Epileptic Response to Gratings
}

\author{
${ }^{*}$ Michael J. Soso, Ettore Lettich, and †Jack H. Belgum \\ Division of Electroencephalography and Clinical Neurophysiology, \\ Department of Laboratory Medicine, and Departments of \\ Physiology/Biophysics and Psychology, University of Washington, \\ Seattle, Washington 98195
}

\begin{abstract}
Summary: Rare individuals suffer epileptic seizures when they view certain images, particularly stripes. Contrast-threshold functions (the ability to see faint stripes of various widths) were determined for two pattern-sensitive brothers, and the epileptogenicity of various patterns was assessed for one of them. Sine wave grating contrast-detection thresholds for the two subjects were essentially normal, with lowest thresholds at approximately 2 cycles/ degree (c/deg). Epileptiform discharges occurred maximally at $5 \mathrm{c} / \mathrm{deg}$ with a 1-octave $50 \%$ bandwidth. Pattern epileptogenicity was increased by the addition of a third harmonic sine wave grating to its fundamental, but was unaffected by the phase relation of the two gratings. The frequency selectivity of epileptic responsiveness was quantitatively similar to a "spatial frequency channel." Inhibitory interactions were not present. The findings suggest relations between the phenomena of pattern-sensitive epilepsy and hypothesized spatial frequency channels which merit further exploration.
\end{abstract}

Pattern-sensitive epilepsy is characterized by seizures precipitated by visual patterns, particularly stripes. This was first described by Bickford et al. (1953). ${ }^{1}$ Chatrian et al. $(1970 a, b)$ qualitatively studied pattern epileptogenicity (the ability of pattern presentation to induce EEG discharge) for their Case 1 by systematically varying grating distance or the separation of grating lines. At the 10 distances tested, their grating produced spatial frequencies ranging from 1.4 to 14 cycles/degree (c/deg). Maximum epileptogenicity occurred between 2.8 and $5.6 \mathrm{c} / \mathrm{deg}$. Varying the line separation produced gratings with spatial frequencies of $1.0,1.5,2.4,4.8,7.2$, and 14

Received November 16, 1979; revised March 4, 1980.

Key words: Pattern-sensitive epilepsy-Spatial frequency channels $\rightarrow$ Sine and square wave gratings.

* Present address: Department of Medicine, Resident, Presbyterian University Hospital, Pittsburgh, Pennsylvania 15213.

† Present address: Department of Physiology, Medical Science Building, The University of Michigan, Ann Arbor, Michigan 48104.

Presented in part at the Western Electroencephalography Society Meeting in Salt Lake City, Utah, February 17, 1978.

A bibliography of publications on pattern-sensitive epilepsy is available from the first author. 
c/deg. The largest response occurred at 4.8 and $7.2 \mathrm{c} / \mathrm{deg}$.

Fourier analysis of the patterns employed by Chatrian et al. (1970a) (Soso, 1975) suggested important interactions between grating fundamentals and their harmonics. For example, they employed a highly epileptogenic square grating with a fundamental spatial frequency of $8.72 \mathrm{c} / \mathrm{deg}$, a $3 f$ harmonic of $26.2 \mathrm{c} / \mathrm{deg}$, and a $5 f$ harmonic of $43.6 \mathrm{c} / \mathrm{deg}$. The $5 f$ harmonic was probably below threshold. Rectangular grating $A$ of their figure 6 had a fundamental of 14.0 c/deg, a $2 f$ harmonic of $28 \mathrm{c} / \mathrm{deg}$, and a $3 f$ harmonic of $42 \mathrm{c} / \mathrm{deg}$; this was nonepileptogenic.

Rectangular grating $E$ of their figure 6 had a fundamental spatial frequency of 8.38 c/deg with $2 f, 3 f$, and $4 f$ harmonics of 16.8 , 25.1 , and 33.5, respectively. This also was not epileptogenic. When a $4.8 \mathrm{c} / \mathrm{deg}$ rectangular grating was defocused, which lowers the relative amplitude of the higher harmonics, epileptogenicity decreased markedly.

This analysis suggests the epileptogenicity depends on a strong fundamental near 5 c/deg and/or a favorable relation between the fundamental and the harmonics (cf. the $8.72 \mathrm{c} / \mathrm{deg}$ square grating to pattern $\mathrm{A}$-the harmonics are similar, but the fundamentals differ; cf. the $8.72 \mathrm{c} / \mathrm{deg}$ square grating to pattern $\mathrm{E}$ - the fundamentals are similar, but the upper harmonics differ; cf. the focused and unfocused rectangular grating).

Their Case 4 was tested with gratings having spatial frequencies from 0.370 to 4.2 c/deg. Responses consistently occurred at $2.7 \mathrm{c} / \mathrm{deg}$ and also, although erratically, at 3.4 and $4.2 \mathrm{c} / \mathrm{deg}$ but did not occur at or below $2.0 \mathrm{c} / \mathrm{deg}$ (Chatrian and Lettich, personal communication).

Wilkins et al. (1979) have contributed the most extensive study of the effect of spatial frequency on pattern epileptogenicity. All of their subjects responded maximally to patterns with spatial frequencies between 1 and $4 \mathrm{c} / \mathrm{deg}$. Four of their subjects re- sponded to relatively narrow ranges of spatial frequency.

The above results suggest spatialfrequency selectivity. The following three sets of experiments represent a progressive analysis, using the techniques of visual psychophysics, of the pattern sensitivity of Case 1 of Chatrian et al. $(1970 a, b)$. The first series of experiments involve measurements of the ability to see faint stripes, a test widely considered to be a powerful method for assessing visual function (Sekuler, 1974) and analogous to modern methods for testing optical systems and many types of transducers. In the second set of experiments, pattern epileptogenicity was tested as a function of two variables, spatial frequency and contrast, in order to determine if their effects are consistent with predictions based on the prior findings discussed above. Finally, experiments are described which use complex gratings (gratings composed of two or more sine gratings) in order to test certain predictions about their effects.

\section{METHODS}

\section{Subjects}

Our subjects were Cases 1 and 2 of Chatrian et al. $(1970 a, b)$. The reader is referred to their paper for detailed histories of these patients. Pertinent recent details are described here.

\section{Case 1}

A 25-year-old male continued to have several generalized seizures each year. The frequency of his staring spells was reduced by increasing his daily dosage of primidone (Mysoline) from $250 \mathrm{mg}$ twice daily to 250 mg 4 times daily. His daily regimen included paramethadione (Paradione), 900 $\mathrm{mg}$; primidone (Mysoline), $1000 \mathrm{mg}$; phenytoin (Dilantin), $100 \mathrm{mg}$; and, occasionally, phenobarbital, $60 \mathrm{mg}$ at bedtime. Repeated general and neurological examinations (Dr. R. J. Wilkus) were within normal 
limits. The patient continued to have a low-grade astigmatism (O.D.: $-0.20+.50$ $\times 180=20 / 20$; O.S.: $-.25+.50 \times 135=$ 20/20). On his current medications, Case 1 was no longer sensitive to intermittent photic stimulation, but retained his pattern sensitivity. He was extremely cooperative throughout the extended present studies.

\section{Case 2}

The 16-year-old brother of Case 1 had a normal general and neurological examination (Dr. R. L. Matthews). He had a mild myopia (O.D.: $-1.50=20 / 20$; O.S.: -2.00 $\times 50=20 / 20$ ). The patient, resenting his clinical diagnosis of pattern-sensitive epilepsy, refused medications for over a year without any ill effects until he suffered a generalized pattern-induced seizure several days before examination. He cooperated adequately during testing.

Both subjects, were consenting, remunerated volunteers, participating with institutional approval. Their safety was insured by continuous EEG monitoring and by restricting pattern presentation times to $10 \mathrm{sec}$, except under special circumstances, at which time additional precautions were taken. At no time did the subjects exhibit any clinical symptoms (including staring, eyelid flutter, or clonic jerking), despite, at times, large electrographic activity.

The control subjects were a 25 -year-old male who wore clinically fitted contact lenses to correct a myopic corrdition and a 24-year-old emmetropic male. Both subjects were experienced with visual psychophysics experiments.

\section{Equipment}

Visual stimuli were produced on an oscilloscope by the method of Campbell and Green (1965). The $x$ - and $y$-axes were modulated by waveform generators to form a raster, which was then modulated by $z$-axis input. Low-contrast sine gratings (stripes with a horizontal sinusoidal luminance profile) were generated by modulating the $z$ - axis (brightness) of a Tektronix 602 oscilloscope with a sine-wave generator. A voltage-controlled wave generator was used to modulate the $z$-axis in order to generate high-contrast square gratings and phase-locked harmonic sine gratings. The generator outputs were applied to the axis through an operational amplifier/mixer. The space-averaged luminance $(L)$ of the grating, 68.5 candles $/ \mathrm{m}^{2}$, was measured daily with a photometer. Percentage contrast, defined as $\left(L_{\max }-L_{\min }\right) /\left(L_{\max }+L_{\min }\right) \times$ $100 \%$, was measured by vernier-scanning a magnified image of the grating with a photomultiplier photometer.

The oscilloscope gratings were viewed binocularly from a distance of $135 \mathrm{~cm}$ except where otherwise indicated. All grating presentations contained a minimum of $\mathbf{1 0}$ cycles of stripes. The display was framed by a $7.3 \times 10.5 \mathrm{~cm}$, similarly colored (yellow-green), but darker (0.343 candles $/ \mathrm{m}^{2}$ ) background. The position of each subject's head was maintained with head and chin rests.

EEG recordings were obtained with a 16-channel electroencephalograph via electrodes placed according to the International 10-20 system, secured with collodion, and filled with conducting jelly.

Electrodes usually included those designated $\mathrm{O}_{1}, \mathrm{P}_{3}, \mathrm{C}_{3}, \mathrm{O}_{2}, \mathrm{P}_{4}$ and $\mathrm{C}_{4}$, with each hemisphere referenced to the contralateral earlobe $A_{1}$ or $A_{2}$. Additional periorbital electrodes recorded electro-oculograms. Other channels were employed to monitor pattern presentations and subject responses. The system bandpass was $0.5-70$. $\mathrm{Hz}(-3 \mathrm{~dB})$ at the inkwriters and 0.5-625 $\mathrm{Hz}(-3 \mathrm{~dB})$ when recorded on an FM magnetic tape recorder.

\section{Procedures}

\section{Contrast-Detection Thresholds}

The ability of the subjects to detect gratings was determined by a modification of the method of limits. As each subject viewed the oscilloscope screen, the con- 
trast of the sinusoidal gratings was increased at variable rates until they were detected. Data were obtained by giving subjects a brief, low-contrast "preview" of the grating and then obtaining measurements from 2 "preliminary" trials (discarded) and 4 to 5 actual trials. This process was repeated for several spatial frequencies. Case 1 participated in 1,234 practice trials before data were collected.

Additional thresholds were obtained for Case 1 by the method of temporal 2alternative forced-choice (Green and Swets, 1966). A pair of $1,000-\mathrm{Hz}$ tones, 2 sec in duration and separated by $0.9 \mathrm{sec}$, indicated the trial. A low-contrast $5 \mathrm{c} / \mathrm{deg}$ sine grating was presented during one of the tone intervals, and the subject's task was to identify which interval of the pair coincided with pattern presentation. Following a brief training period, 562 measurements were made utilizing pattern contrast ranging from $.078 \%$ to $.83 \%$ contrast.

\section{Pattern Epileptogenicity}

While Case 1 viewed the oscilloscope screen with a steady gaze, a faint sine or square grating (stripes with blurred or sharp edges, respectively) was presented for 10 sec, five times in succession, with interpresentation intervals of 10 to 15 sec. After each series of 5 presentations, contrast was raised by $3 \mathrm{~dB}$ until the limit of scope contrast linearity, approximately $85 \%$, was attained. This process was performed at spatial frequencies of $2,5,7$, and $9 \mathrm{c} / \mathrm{deg}$ and occasionally at 1 and $10 \mathrm{c} / \mathrm{deg}$. All gratings were vertical and stationary. Epileptiform discharges in the form of spikes or multiple spikes, alone or associated with slow waves, occurring in the 6 EEG leads during the 5 presentations were totaled and constitute the data presented in the following graphs and tables. The spikes counted were transients larger in amplitude than the background activity with a total duration of 20 to 70 msec (Chatrian et al., 1974). Every spike occurring in the 6 electrode tracings was identified by two observers (M. J. S. and E. L.) and tabulated. Typical discharges are illustrated in Fig. 2.

\section{Responses to Complex Gratings}

Complex gratings consist of two or more superimposed sine gratings. By this definition, a square grating is a complex grating composed of an infinite series of sine gratings. The relationships among sine, square, and complex $(5+15 \mathrm{c} / \mathrm{deg})$ gratings were examined with three types of tests. On some experimental days, spike discharges in response to both sine and square gratings equalized for peak-to-peak contrast were collected in the manner described above. In the second type of test, vertical sine gratings of 5 and $15 \mathrm{c} / \mathrm{deg}$ were superimposed in a subtractive ("square") phase relation, with the amplitude of the $15 \mathrm{c} / \mathrm{deg}$ grating equal to $1 / 3$ that of the $5 \mathrm{c} / \mathrm{deg}$ grating. This complex grating constitutes the first two components of a square grating. Series of 5 presentations of this complex grating were alternated with 5 presentations of the fundamental alone. This test was an approximate comparison of sine and square gratings equalized for contrast of their fundamentals. In the third type of test, the phase relations between the third harmonic and the fundamental were varied so that the peaks either subtracted (square wave configuration) or added ("triangle" wave configuration). Detection thresholds for the two phase relations were determined by the method of 2-alternative forced-choice. The epileptic discharges produced by the two phase relations were examined by alternating the two conditions every other, every second, or every fifth presentation.

\section{RESULTS}

\section{Contrast-Detection Thresholds}

For Case 1 and the control subject (Fig. 1), linearly increasing spatial frequency (decreasing stripe width) required an approximately logarithmic increase of contrast to permit detection. Case 1 , however, required 10 to $12 \mathrm{~dB}$ more contrast (approximately 4 times as much contrast) at 


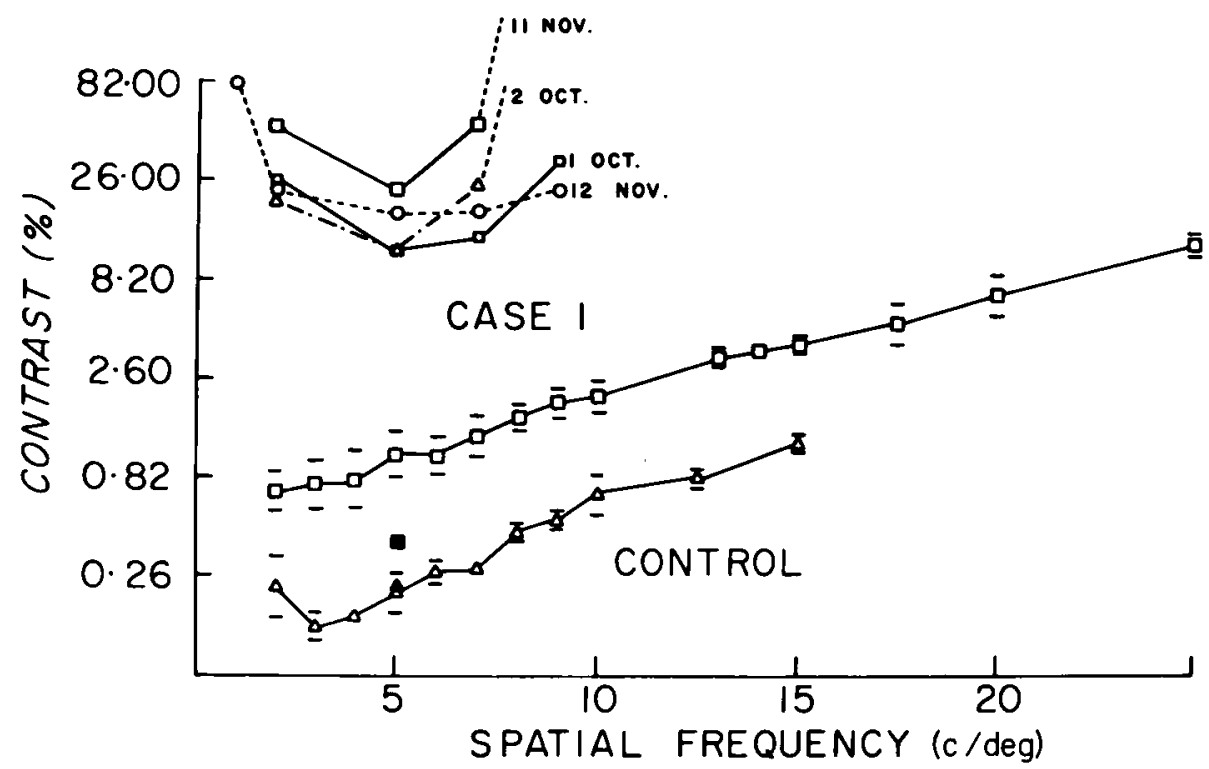

FIG. 1. Contrast detection and discharge thresholds. Thresholds for pattern detection and epileptogenesis are plotted as a function of spatial frequency and contrast of a vertical grating presented at a distance of $135 \mathrm{~cm}$ except for $17.5,20$, and $25 \mathrm{c} / \mathrm{deg}$, which were obtained at $270 \mathrm{~cm}$. The bottom curve $(\triangle)$ presents the thresholds for detection of a sine grating by a control subject ( 94 determinations). The upper curve ( $\square$ ) presents the thresholds of Case 1 ( 205 determinations). The filled square and triangle represent the 2-alternative forced-choice thresholds for Case 1 and the control subject, respectively, determined for $5 \mathrm{c} / \mathrm{deg}$. The smaller upper curves represent the onset of epileptiform discharges in the EEG of Case 1 as contrast was increased (see text). On 11 Nov. and 2 Oct., thresholds for discharge at $9 \mathrm{c} / \mathrm{deg}$ were not reached, and this is indicated by upgoing dashed lines.

each spatial frequency before his criterion for detection was met. Thresholds for Case 2 were similar to those of the control subjects.
The criterion-free method of 2-alternative forced-choice was employed to determine how much of the threshold difference between Case 1 and the control subjects was

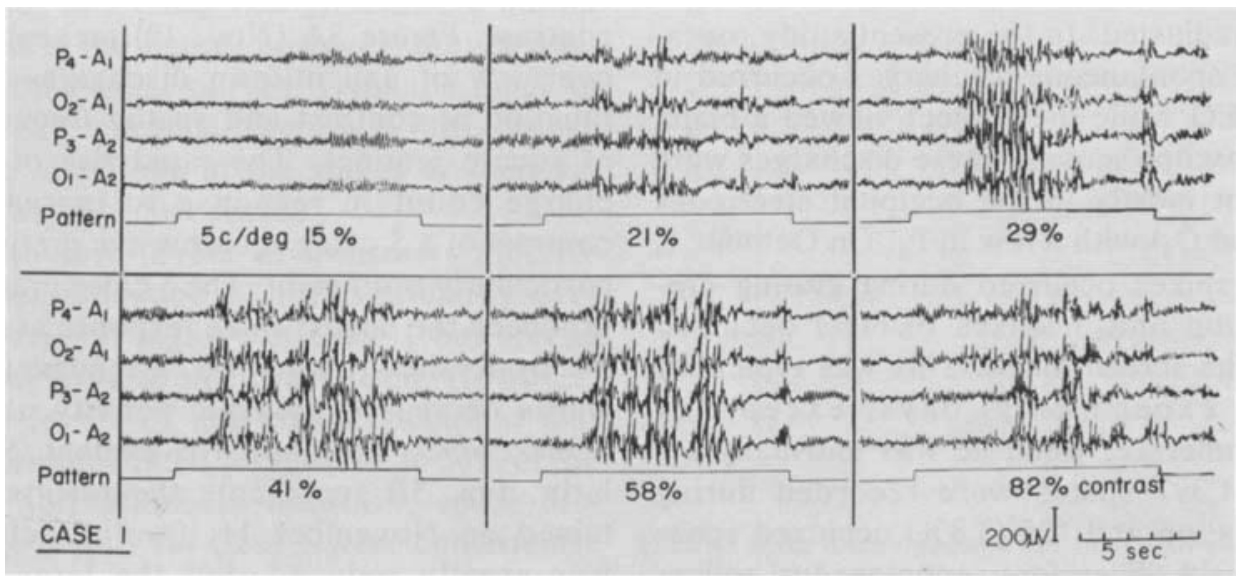

FIG. 2. Effect of contrast changes. EEG tracings recorded during the presentation of vertical square gratings demonstrate the effects of increasing contrast from 15 to $82 \%$. The line labeled "pattern" represents a gating voltage which turned on pattern presentation. 


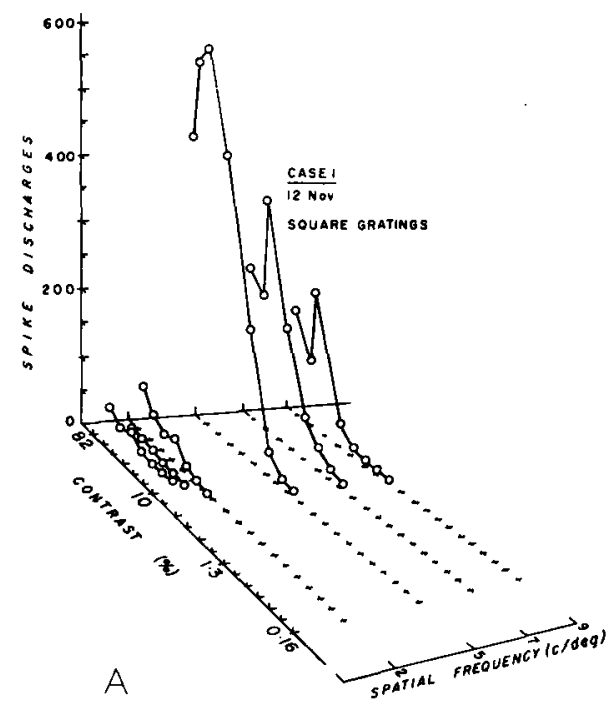

due to criterion rather than ability to detect faint gratings (Kelly and Savoie, 1973). Threshold (75\% correct) occurred at $0.36 \%$ contrast. The control subject's threshold was $0.23 \%$ contrast. Thus, Case 1 required $4 \mathrm{~dB}$ (1.58 times) as much contrast to detect the stripes as did the control subject.

\section{Pattern Epileptogenicity}

It is worth noting that "occasional, apparently spontaneous" discharges were observed by Chatrian et al. $(1970 a, b)$. At that time, Case 1 was new to the clinic and his medication regimen had not yet been optimally adjusted. In the present study, occasional spontaneous discharges occurred in the EEG while the subject viewed a blank oscilloscope screen. These discharges were present mostly in the occipital electrodes $\left(\mathrm{O}_{1}\right.$ and $\left.\mathrm{O}_{2}\right)$ with a few in $\mathrm{P}_{4}$. On October 1 , 2,838 spikes occurred during grating presentation and 3 spikes $(0.11 \%)$ occurred with the screen blank. This was typical of other experimental days, except for November 12, when he was unusually active: 4,397 spikes were recorded during stimulation and $125(2.8 \%)$ occurred spontaneously. Therefore, spontaneous epileptiform activity formed only a small part of the total epileptiform discharges.

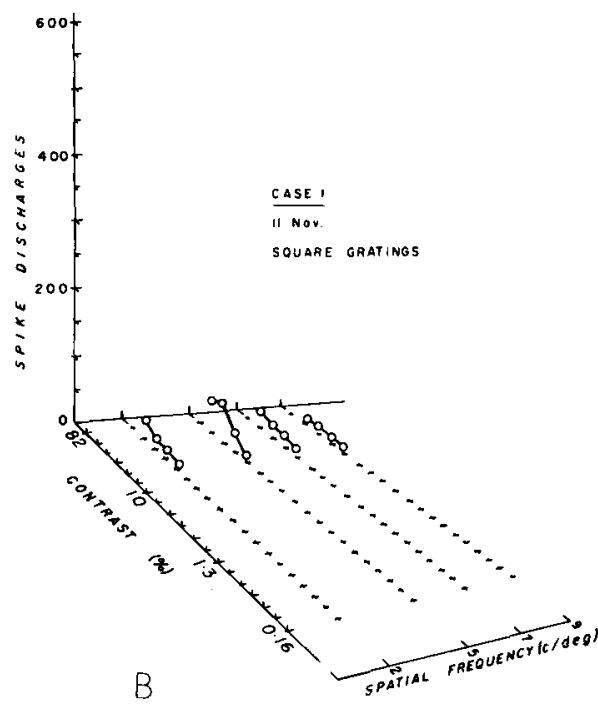

As pattern contrast was increased, epileptiform discharges eventually appeared in the EEG. The top four lines of Fig. 1 represent the contrast thresholds of Case 1 for electrographic epileptic discharge in response to square-grating presentations on 4 different days. The criterion for threshold was a total of 20 spikes during the 5 presentations. The results indicate that less contrast was necessary for discharge at 5 and $7 \mathrm{c} / \mathrm{deg}$ than at the other spatial frequencies.

The EEG tracings depicted in Fig. 2 show epileptiform discharges as a function of contrast. Figure 3A (Nov. 12) presents an overview of epileptiform discharges as a function of contrast and spatial frequency of square gratings. The rapid rise of discharge count in response to increasing contrast of a $5 \mathrm{c} / \mathrm{deg}$ square wave grating is particularly prominent. The $5 \mathrm{c} / \mathrm{deg}$ gratings produced the largest spike response at each electrode site. In addition, a tendency towards decreased epileptic activity at the highest levels of contrast is evident. Similarly, Fig. 3B represents the results obtained on November 11. Overall activity was greatly reduced, but the larger response at $5 \mathrm{c} / \mathrm{deg}$ with a high-contrast rolloff is still apparent. In general, results ob- 


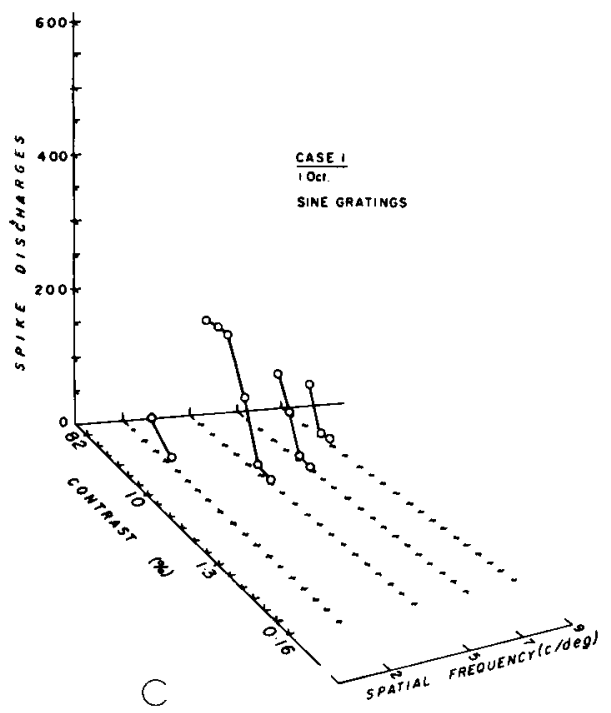

tained with sine gratings showed the same features, with fewer epileptic discharges (Fig. 3C).

The responses of Case 1 to increasing contrast of a $5 \mathrm{c} / \mathrm{deg}$ square grating on different days are plotted in Fig. 4. This figure indicates that responses usually began as contrast exceeded $10 \%$ and then increased approximately linearly as a function of the logarithm of contrast, with a roll-off in responsiveness at high levels of contrast. The slope of the responsiveness varied from day to day, however. For reasons of clarity, responses to $5 \mathrm{c} / \mathrm{deg}$ sine gratings are not included in the figure; however, they lay between the other curves. Over the range of 21 to $82 \%$ contrast, there was little change in the amplitude of the spikes or their accompanying slow waves.

With low levels of contrast, electrographic activation occurred primarily over the occipital regions of Case 1 but spread anteriorly as contrast increased. However, at all levels of activation, occipital discharges accounted for more than $50 \%$ of the total activation. In addition, spike discharge counts for Case 1 were consistently larger over the right hemisphere. These relationships are plotted in Fig. 5.

When spatial frequency was varied while
FIG. 3. Epileptiform discharges in response to gratings. The spike discharges occurring during five 10-sec grating presentations were totaled over 6 EEG leads and are presented as a function of grating spatial frequency ( $x$-axis) and grating contrast ( $z$-axis). $\mathbf{A}$ : $\mathbf{R e}$ sponse to square grating (Nov. 12). B: Response to square gratings (Nov. 11), C: Response to sine gratings (Oct. 1).

contrast was held constant, the amount of epileptic discharges changed as in Fig. 6A,B. For both sine and square gratings, discharge was greatest at $5 \mathrm{c} / \mathrm{deg}$, falling off rapidly at lower and higher spatial frequencies. The $50 \%$ bandwidths (the values of spatial frequency at which discharge counts

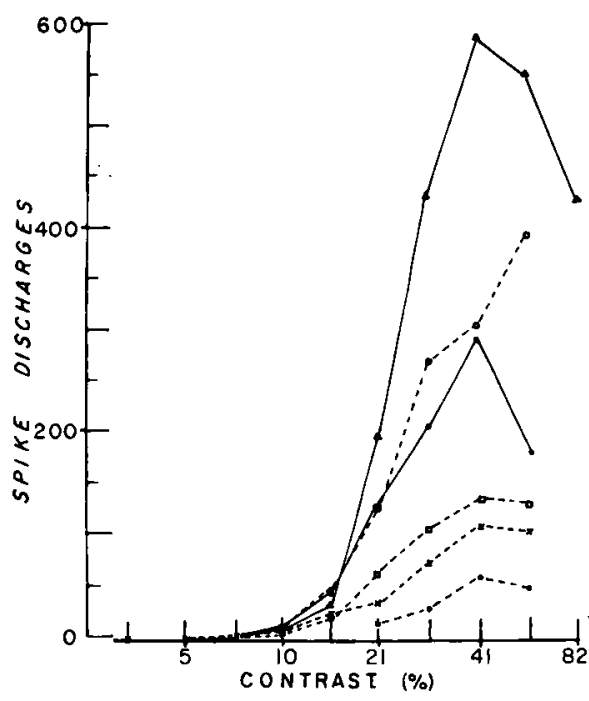

FIG. 4. Spike discharges as a function of grating contrast. The total spike discharges occurring during five 10 -sec, 5 c/deg square-grating presentations are plotted as a function of grating contrast. Results obtained on 6 different days are depicted. 

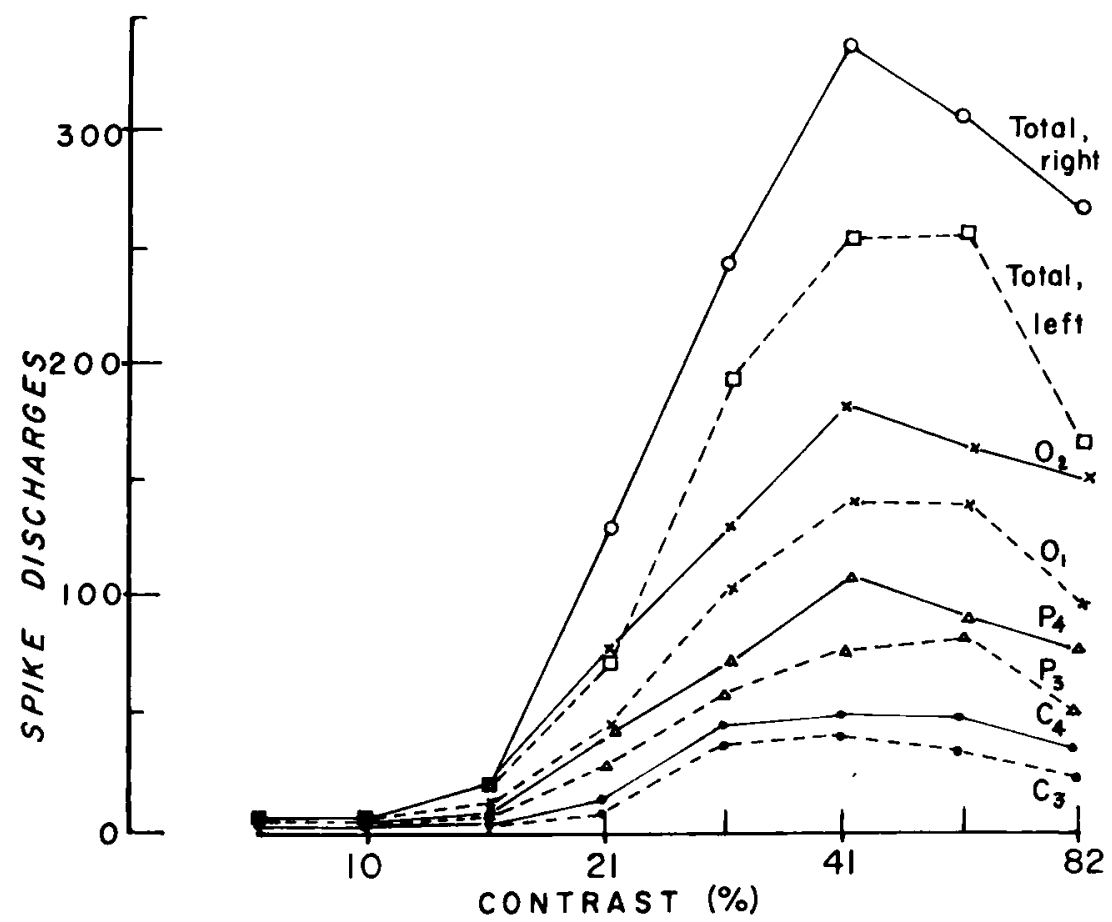

FIG. 5. Discharge spread as a function of contrast. The spikes occurring in each of six EEG electrodes during five 10-sec presentations of a $5 \mathrm{c} / \mathrm{deg}$ square grating are plotted as a function of the grating contrast.

are $50 \%$ of maximum) for both square and sine gratings were just over 1 octave of spatial frequency. Activation was never observed at $10 \mathrm{c} / \mathrm{deg}$.

\section{Responses to Complex Gratings}

Detection thresholds were determined for Case 1 by a temporal 2-alternative forced-choice procedure for complex gratings consisting of the fundamental $(5 \mathrm{c} / \mathrm{deg})$ and the third harmonic in either the peaksadd or the peaks-subtract phase relation. The responses were identical for the two conditions: $100 \%$ correct at $0.41 \%$ contrast (10 comparisons), $64 \%$ correct at $0.36 \%$ contrast ( 25 comparisons), and $55 \%$ correct at $0.33 \%$ contrast (20 comparisons). The best estimate of threshold ( $75 \%$ correct) would be $0.36 \%$ contrast, the same value as was obtained for the $5 \mathrm{c} / \mathrm{deg}$ sine grating without harmonics.

When responses to sine and square gratings equalized for peak-to-peak contrast were compared, it was found, as mentioned above, that square gratings usually evoked more spike discharges. Examining results obtained on single days revealed 21 pairs of values where both gratings elicited an adequate count of epileptic discharges to permit comparison (sine wave gratings frequently evoked no discharges, and in those instances no comparison of relative epileptogenicity was possible). When the discharges elicited by the sine gratings are expressed as a percentage of the discharges produced by square gratings of the same contrast and spatial frequency, values were found to range from 29 to $143 \%$, with a mean and standard deviation of $69 \pm 28 \%$ and a median and mode of $64 \%$. The differences between sine and square grating responses were significant $(p<<0.01$, signed-rank test).

A comparison of the response to a sine grating with the same grating combined subtractively with its third harmonic also 

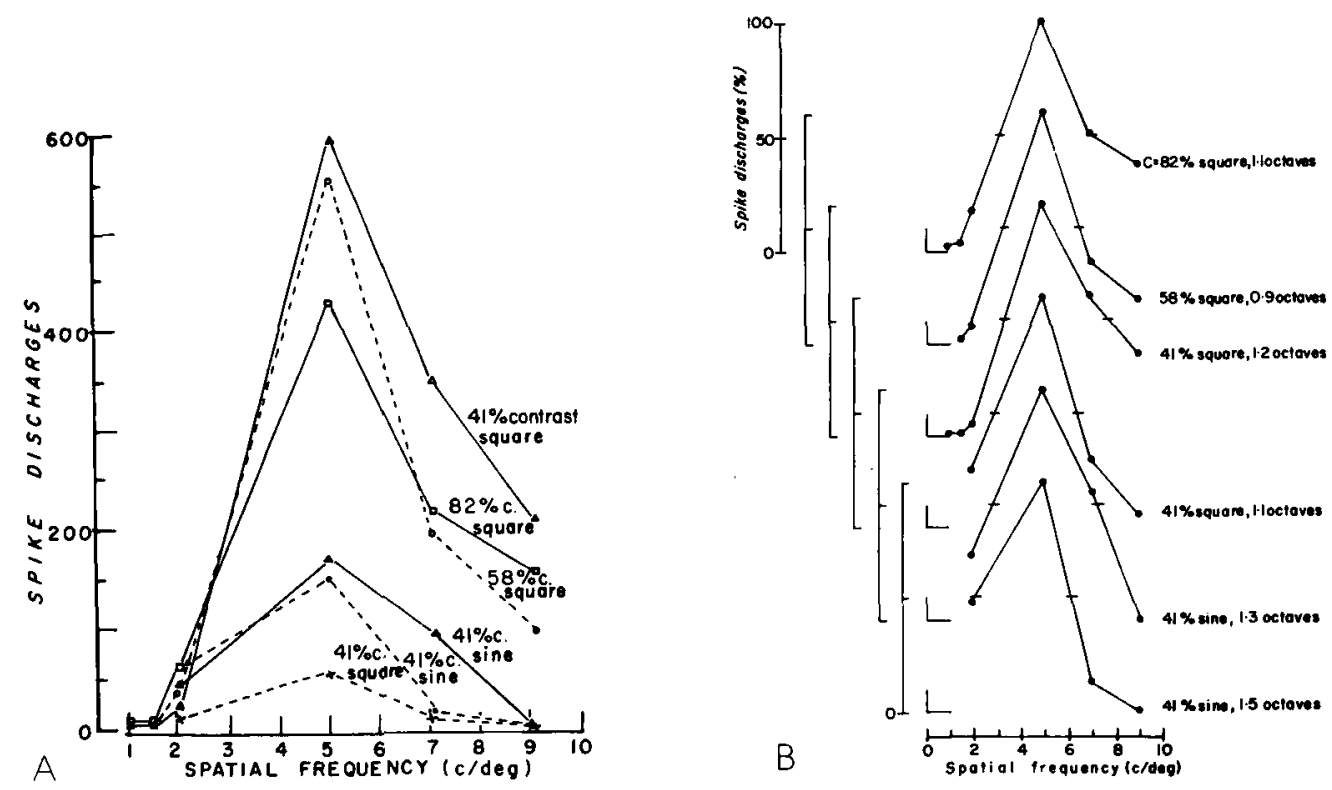

FIG. 6. Spatial frequency bandwidths for sine and square grating epileptogenesis. Results obtained on several different days. A. Isocontrast plots of the total spike discharges during five 10 -sec presentations graphed as a function of spatial frequency. B. Spike discharge counts normalized with $100 \%$ for the 5 c/deg gratings and corresponding percentages for the lower and higher frequencies presented for various contrast levels and bandwidths (in octaves) at $50 \%$.

revealed the sine grating to be less epileptogenic than the complex square grating. At 15,21 , and $29 \%$ contrasts, the sine gratings elicited $43 \%$ (15 comparisons), $72 \%$ ( 25 comparisons), and $75 \%$ (15 comparisons), respectively, of the responses elicited by the complex square grating. These differences were significant $(p<0.05$, signedrank test).

Epileptiform discharges produced by the add and subtract phase relations were examined at 41,29 , and $21 \%$ contrast. At these three levels of contrast, the comparisons produced a total of (subtract vs add) 1,564 vs 1,184 (57 comparisons), 806 vs 829 (69 comparisons), and 74 vs 106 (20 comparisons) spike discharges. These differences were not significant ( $p>0.1$, Wilcoxon matched-pairs, signed-ranks test).

\section{DISCUSSION}

\section{Contrast-Detection Thresholds}

The results of the 2-alternative forcedchoice threshold measurements indicate that most of the difference in thresholds, displayed in Fig. 1, were a result of differences in threshold criteria. The form of the threshold curve of Case 1 resembles that of the control subject and contrast-detection curves published in the literature (Campbell and Green, 1965; Hoekstra et al., 1974). Contrast-threshold curves are a convenient summary of visual system performance, may allow predictions of visual system response, and have an important relation to theories which propose multiple stripewidth channels and Fourier analysis processing in the visual system (Sekuler, 1974). Studies of this type have already proven valuable for the analysis of certain neurological disorders (Bodis-Wollner, 1972, 1976; Regan et al., 1977; Soso and McCutchen, 1978). Given these considerations and the nature of the disorder in Cases 1 and 2, their normal contrastdetection abilities suggest that they enjoy normal spatial vision for images containing low-contrast spatial frequencies. 


\section{Pattern Epileptogenicity}

In general, most discussions of patternsensitive epilepsy have interpreted this phenomenon in terms of visual cortex cell receptive fields (Hubel and Wiesel, 1968). If one postulated some form of global instability in these cells, a sufficient stimulus for epileptogenesis might be a certain increment of contrast above threshold. Wilkins et al. (1979) found their subjects to be most responsive to gratings of 1 to $4 \mathrm{c} / \mathrm{deg}$ and noted that some studies of contrast detection found peak detection sensitivity at 4 to $6 \mathrm{c} / \mathrm{deg}$. They cite this concordance as support for the proposal that epileptogenicity depends on "the number of cells firing in excess of threshold." The concordance is spurious, however, because peak detection sensitivity is a property of display parameters, not of the nervous system (Hoekstra et al., 1974). Our display, designed with these considerations in mind, produced, as expected, peak detection sensitivity at about 1 to $2 \mathrm{c} / \mathrm{deg}$. Discharge thresholds determined with the same equipment did not parallel detection thresholds (Fig. 1). This divergence was even more obvious at high contrast (Fig. 3). These results argue against a "mass-action" hypothesis of epileptogenesis; stimulus "quality" is in certain respects more important than "quantity."

Wilkins et al. (1979) measured epileptogenicity by determining the probability of response rather than the response per se. Despite this difference, the spatial frequency bandwidth for epileptogenesis was similar for their patients and ours. Two of their 8 subjects had bandwidths near 1 octave, and 2 others had bandwidths of less than 2 octaves. Case 4 of Chatrian et al. (1970a), although not extensively studied, was apparently very spatial-frequency selective. Case A.M. of Sacquegna et al. (1976) responded more than 2 times as much to $3 \mathrm{c} / \mathrm{deg}$ gratings as compared to 1.5 $\mathrm{c} / \mathrm{deg}$ gratings. Without data about the responses to higher spatial frequencies, no conclusions can be made, but their results are not inconsistent with a $50 \%$ bandwidth of 1 octave.

This demonstration of spatial-frequency selectivity suggests relationships to proposed spatial-frequency channels in human vision. ${ }^{1}$ In general, the channel bandwidths estimated from threshold techniques (Sachs et al., 1971) have been less than 1 octave, while those derived from adaptation (Blakemore et al., 1970; DeValois, 1977) and masking (Carter and Henning, 1971; Stromeyer and Julesz, 1974) have been slightly greater than 1 octave. However, there are models which account for all the bandwidth estimates using an assumption of a basic bandwidth of approximately 1 octave (Graham, 1977; Cowan, 1977).

The spatial-frequency $50 \%$ bandwidth for epileptogenesis in Case 1 corresponds with the bandwidths determined by masking and adaptation experiments. Perhaps his basic disorder involves one or a few adjacent spatial-frequency channels. If this is the case, epileptiform discharges represent an objective indicator with which to examine the activity of these channels and thereby determine their neural and psychophysical "structure."

\section{Responses to Complex Gratings}

Graham and Nachmias (1971) demonstrated independent thresholds for the fundamental and third harmonics of complex

\footnotetext{
'Addendum: These channels are hypothetical constructs proposed to explain various visual psychophysics data. The data suggest that the human visual system contains detectors (channels) tuned to small ranges of stripe widths (spatial frequencies). In essence the channels are postulated to perform like filters for the stripe content of visual images. Parenthetically, it is relevant to point out that some authors have suggested that these filters begin a Fourier-like analysis of the visual field by decomposing images into the spectra of their stripe content, a proposal relavant to Part II.
} 
gratings. Case 1 also detects the components of a complex $(5+15 \mathrm{c} / \mathrm{deg})$ grating independently. Above threshold, however, the components were not independent, since the addition of a normally ineffective $15 \mathrm{c} / \mathrm{deg}$ sine grating greatly enhanced the epileptogenicity of a $5 \mathrm{c} / \mathrm{deg}$ sine grating. This increased epileptogenicity was not affected by the phase of the third harmonic; perhaps pattern epileptogenicity is related to the root-mean-square contrast.

The increased epileptogenesis caused by the third harmonic is consistent with a recent report of a facilitatory interaction between spatial-frequency channels separated by 1 to 2 octaves (DeValois, 1977; Tolhurst and Barfield, 1978). Alternatively, the third harmonic excitation may represent one aspect of the as yet unknown fundamental disorder in the visual system of Case 1 which predisposes him to pattern-induced seizures.

The intent of these experiments was to delineate the relationships, if any, between pattern-sensitive epilepsy and multiple spatial-frequency channels in human vision. The findings of a spatial-frequency selective phenomena suggests that further study of pattern-sensitive epilepsy will provide insight into the processes of vision and epilepsy.

\section{ACKNOWLEDGMENT}

We gratefully acknowledge the following contributions. Dr. Gian Emilio Chatrian provided laboratory facilities, invaluable assistance, and data from previous studies; Dr. Robert J. Wilkus attended the patients during their hospitalization for these studies; Dr. Davida Y. Teller gave critical encouragement in the early stages of the project and, along with Dr. Janusz J. Kulikowski, contributed many valuable suggestions. This work was supported in part by NINCDS Grant 11563-01, an Epilepsy Foundation of America Grant, NIH Clinical Research Center Grant RR-37, NIH Grant NS0453, and PHS Training Grant 5T01 GM 666.

\section{REFERENCES}

Bickford RG, Daly D, and Keith M. Convulsive effects of light stimulation in children. Am J Dis Child 86: $170-178,1953$.

Blakemore C, Nachmias J, and Sutton P. The perceived spatial frequency shift: Evidence for frequency-selective neurons in the human brain. $J$ Physiol (Lond) 210:727-750, 1970.

Bodis-Wollner $I$. Visual acuity and contrast sensitivity in patients with cerebral lesions. Science 978:769-771, 1972.

Bodis-Wollner I. Vulnerability of spatial frequency channels in cerebral lesions. Nature 261:309-311, 1976.

Campbell FW and Green DG. Optical and retinal factors affecting visual resolution. J Physiol (Lond) 181:576-593, 1965.

Carter BE and Henning GB. The detection of gratings in narrow-band visual noise. $J$ Physiol (Lond) 219:355-365, 1971 .

Chatrian GE, Lettich E, Miller LH, and Green JR. Pattern-sensitive epilepsy. 1. An electrographic study of its mechanisms. Epilepsia (Amst) 11:125-149, 1970a.

Chatrian GE, Lettich E, Miller LH, Green JR, and Kupfer C. Pattern-sensitive epilepsy. 2. Clinical changes, tests of responsiveness and motor output, alterations of evoked potentials and therapeutic measures. Epilepsia (Amst) 11:151-162, 1970 b.

Chatrian GE, Bergamini L, Dondey $M$, Klass DW, Lennox-Buchthal $M$, and Petersen 1 . A glossary of terms most commonly used by clinical electroencephalographers. Electroencephalogr Clin Neurophysiol 37:538-548, 1974.

Cowan JD. Some remarks on channel bandwidths for visual contrast detection. In: Poppel E, Held R, and Dowling JE (Eds), Neuronal Mechanisms in Visual Perception, Neurosciences Research Program Bull 1977, 15:492-517.

DeValois K. Spatial frequency adaptation can enhance contrast sensitivity. Vision Res 17:1057-1065, 1977:

Graham N. Visual detection of aperiodic spatial stimuli by probability summation along narrow band channels. Vision Res 17:634-652, 1977.

Graham N and Nachmias J. Detection of grating patterns containing two spatial frequencies: A comparison of single-channel and multiple channel model. Vision Res 11:251-259, 1971.

Green DM and Swets JA. Signal Detection Theory and Psychophysics. Wiley, New York, 1966, 428 pp.

Hoekstra J, van der Groot DPJ, van den Brink G, and Bilsen FA. The influence of the number of cycles upon the visual contrast threshold for spatial sine wave patterns. Vision Res 14:365-369, 1974.

Hubel HD and Wiesel TN. Receptive fields and functional architecture of monkey striate cortex. $J$ Physiol (Lond) 195:215-243, 1968.

Kelly DH and Savoie RE. A study of sine-wave contrast sensitivity by two psychophysical methods. Percept Psychophys 14:313-318, 1973.

Regan D, Silver R, and Murray TJ. Visual acuity and contrast sensitivity in multiple sclerosis-hidden visual loss. Brain 100:563-579, 1977. 
Sachs MB, Nachmias J, and Robson JG. Spatialfrequency channels in human vision. $J$ Opt Soc Am 61:1176-1186, 1971.

Sacquegna T, Passaglia P, Ambrosetto G, Forti A, and Rossi PG. Epilessia riflessa autoindotta da fissazione di superfici finemente strutturate (Patternsensitive epilepsy). Riv Neurol 46:431-440, 1976.

Sekuler, R. Spatial vision. Annu Rev Psychol 25: 195-232, 1974.

Soso MJ. Pattern-sensitive epilepsy and spatial frequency channels in the human visual system. Electroencephalogr Clin Neurophysiol 38:551, 1975.

Soso MJ and McCutchen CM. Grating contrast detection perimetry in a patient with occipital lobe epilepsy. Neurology 28:870-873, 1978.

Stromeyer CF and Julesz B. Spatial-frequency masking in vision: Critical bands and spread of masking. J Opt Soc Am 62:1221-1232, 1972.

Tolhurst DJ and Barfield LP. Interactions between spatial frequency channels. Vision Res 18:951-958, 1978.

Wilkins AJ, Darby CE, and Binnie CD. Neurophysiological aspects of pattern-sensitive epilepsy. Brain 102:1-25, 1979.

\section{RESUMEN}

De manera excepcional, hay personas que pueden tener ataques epilépticos cuando ven ciertas imágenes, particularmente rayas. Se determinaron los umbrales para contrastes (la capacidad de ver rayas de diversas anchuras y muy tenues) en dos hermanos sensibles a patrones y se estableció la epileptogeneidad de diversos patrones en uno de ellos. Los umbrales para contrastes fueron esencialmente normales en los dos sujetos cuando se utilizó una rejilla hecha con ondas sinusoidales, siendo el umbral inferior unos 2 ciclos/ grado (c/deg). Descargas epileptiformes tuvieron lugar de modo máximo a $5 \mathrm{c} / \mathrm{deg}$ con una amplitud de banda del $50 \%$ de una octava. la capacidad epileptogénica del patrón aumentó cuando se añadió una tercera sinusoide armónica a la rejilla base pero esa capacidad no se vió alterada por la relación de fase entre las dos rejillas. La selectividad de la frecuencia de la respuesta epileptogénica fue cuantitativamente similar al "canal de frecuencia espacial". No se observaron interacciones inhibitorias. Los hallazgos sugieren que hay relaciones entre la epilepsía secundaria a patrones visuales y los hipotéticos canales de frecuencia espacial, lo cual merece más investigación.

(A. Portera Sanchez, Madrid)

\section{ZUSAMMENFASSUNG}

Selten leiden Patienten unter epileptischen Anfällen, wenn sie bestimmte Bilder, insbesondere Streifen sich anschauen. Die Schwellenfunktion gegenüber Kontrasten (die Fähigkeit blasse Streifen verschiedener Weiten zu sehen) wurden bei 2 musterempfindlichen Brüdern bestimmt und die Epileptogenität der verschiedenen Muster bei einem von ihnen ermittelt. Die Erkennungsschwelle für Sinuswellen-Kontrastgitter bei den beiden Patienten war völlig normal; die niedrigsten Schwellen betrugen annähernd 2 Schwingungen pro Grad (c/deg). Die epileptischen Entladungen ereigneten sich maximal bei $5 \mathrm{c} / \mathrm{deg} \mathrm{mit}$ einer 50 prozentigen Bandweite für eine Oktave. Die Epileptogenität des Musters wurde vermehrt durch Addition eines 3. harmonischen Sinuswellenrasters, blieb aber durch die Phasenbeziehung der beiden Raster unbeeinflusst. Die selektive Häufigkeit der epileptischen Antwort war quantitativ ähnlich einem "räumlichen Frequenzkanal". Inhibitionen kamen nicht vor. Die Befunde lassen Beziehungen vermuten zwischen dem Phänomen der Musterepilepsie und hypothetischen räumlichen Kanalfrequenzen, die weiter untersucht werden müssen.

(D. Scheffner, Heidelberg)

\section{RÉSUMÉ}

Quelques individus présentent des crises d'épilepsie quand ils regardent certaines images et en particulier des rayures. Nous avons déterminés le seuil de contraste (c'est-à-dire la possibilité de discerner les rayures peu contrastées de différentes largeurs) chez deux frères trés sensibles à ce genre d'image: pour l'un d'entre eux, nous avons également déterminé le seuil épileptogène à de telles images. Chez les 2 sujets, les seuils de détection des contrastes de grilles variant de façon sinusoidale étaient sensiblement normaux, avec cependant les seuils les plus bas pour approximativement deux cycles par degré. Les décharges épileptiformes apparaissent de façon maximale a 5 cycles $/^{\circ}$, avec une largeur de bande à $50 \%$ de 1 octave. Le pouvoir épileptogène des figures était augmenté si on ajoutait à la grille de variation sinusoïdale la 3eme harmonique du fondamental, mais le pouvoir épileptogène n'était pas modifié en faisant varier les relations de phase des 2 grilles. La susceptibilité épileptogène en fonction de la sélectivité de fréquence était quantitativement semblable a un "canal de fréquence spatiale". Il n'existait pas d'interréaction inhibitrice. Ces résultats suggèrent qu'il existe des relations entre l'épilepsie induite par des images et d'hypothétiques "canaux de fréquence spatiale" qui mériteraient les investigations ultérieures.

(J. Corriol, Marseilles) 